\title{
Mineral content of ionomer cements and preventive effect of these cements against white spot lesions around restorations
}

\begin{abstract}
Lilian Fernanda Santos PAIVA(a) Tatiana Kelly da Silva FIDALGO(b) Lucianne Cople MAIA ${ }^{(b)}$
\end{abstract}

(a) Department of Metallurgical and Materials Engineering, PEMM/COPPE, Universidade Federal do Rio de Janeiro - UFRJ, Rio de Janeiro, RJ, Brazil.

(b)Department of Pediatric Dentistry and Orthodontics, School of Dentistry, Universidade Federal do Rio de Janeiro UFRJ, Rio de Janeiro, RJ, Brazil.

Declaration of Interests: The authors certify that they have no commercial or associative interest that represents a conflict of interest in connection with the manuscript.

\section{Corresponding Author:}

Lucianne Cople Maia

E-mail: rorefa@terra.com.br

DOI: 10.1590/1807-3107BOR-2014.vol28.0034 Epub XxX XX, 2014

Submitted: Sep 12,2013

Accepted for publication: Mar 31, 2014

Last revision: Jul 22, 2014

\begin{abstract}
This study evaluated the ion exchange at the material/enamel interface and the preventive effect of restorative materials submitted to cariogenic challenge against white spot. Restorations in enamel/dentin of bovine teeth were performed with composite resin (Filtek ${ }^{\mathrm{TM}}$ Z250 - control group) and glass-ionomers cements - GICs (Ionomaster R $\mathrm{R}^{\mathrm{TM}}$ and Fuji IX ${ }^{\mathrm{TM}}$ - experimental groups). Samples were grouped and submitted to neutral saliva $(n=15)$ or $\mathrm{pH}$-cycling regimen $(n=15)$. After eight days of $\mathrm{pH}$ cycling, material/enamel interfaces were analyzed by EDX in order to determine the differences $(p<0.05)$ in ionic exchange $(\mathrm{Ca}, \mathrm{P}, \mathrm{F}, \mathrm{Al}, \mathrm{Sr}$, and $\mathrm{Si}$ ) between restorative materials and teeth. In addition, enamel white spot lesion formation was evaluated macroscopically $(p<0.05)$. Sr content was higher in the enamel of the control group $(p>0.05)$ versus the experimental groups. Ca and $\mathrm{P}$ content were higher in enamel than in restorative materials. After $\mathrm{pH}$ cycling, the GIC enamel bulk showed a significantly higher Sr content compared with the composite resin $(p<0.05)$. Filtek ${ }^{\mathrm{TM}} \mathrm{Z} 250$ was not able to prevent white spot formation around restorations in comparison with Ionomaster $\mathrm{R}^{\mathrm{TM}}(p<0.001)$ and Fuji IX ${ }^{\mathrm{TM}}(p=0.004)$. GICs reduced white spot formation and presented a preventive effect $(p=0.051)$. GICs presented a greater percentage of fluoride, aluminum, and strontium, and proved effective in white spot lesion prevention around restorations.
\end{abstract}

Keywords: Tooth; Ion Exchange; Hydrogen-Ion Concentration.

\section{Introduction}

The development of reliable materials to complement sparing approaches and minimal intervention dentistry is an ongoing pursuit. ${ }^{1,2,3,4}$ Glassionomer cements (GICs) have been used for over 20 years in dentistry as important tools in caries prevention. ${ }^{1,4,5,6}$ Certain GIC properties indicate that it is a "smart material"; these include ion exchange and recharge between conventional GICs and the external environment, a thermal expansion coefficient similar to teeth, and chemical adhesion to tooth enamel and dentin. ${ }^{3,7}$

High-viscosity restorative glass ionomers were introduced into dentistry because of their promising attribute of enhancing mechanical properties of cements, ${ }^{8}$ and their ability to remineralize carious tissue remaining after hand excavation ${ }^{9}$ and to prevent secondary caries. ${ }^{10}$ Restorative GIC is a rich reservoir of apatite-forming ions, such as fluoride $(\mathrm{F})$, calcium 
$(\mathrm{Ca})$, strontium $(\mathrm{Sr})$ and phosphate $(\mathrm{P})$, and both $\mathrm{F}$ and Ca ions were found to migrate from GIC to the softened dentin left at the base of cavities.,10,11 This exchange was found to harden the surface of the GIC. ${ }^{7,12}$ According to Ab-Ghani et al., ${ }^{13}$ the depth of exchange between the GIC and the area surrounding the tooth does not exceed $50 \mu \mathrm{m}$. For this reason, this zone of the teeth is of major importance in determining ion incorporation in cases of remineralization, in studies evaluating ionic exchange.

The fluoride release of GIC is dependent on the composition of glass powder and liquid. 14,15,16,17 Some changes have also been made in the glass composition to improve anticariogenic properties ${ }^{10}$ and to promote the formation of a chemical bond with tooth apatite, ${ }^{13}$ by substituting Ca with the Sr content. However, the role of other GIC ions in preventing caries when submitted to a cariogenic challenge is still unknown. Acidic conditions can be expected to promote both demineralization around the restoration and white spot lesions in superficial enamel. Otherwise, the release of ions from GICs is known to be higher at low pHs. ${ }^{5}$ However, incorporating $\mathrm{Ca}$ and $\mathrm{Sr}$ into the area surrounding the teeth, in acidic conditions, has not been correlated to the formation of white spot lesions.

The aim of this study was to evaluate the relationship between the presence and incorporation of the mineral content (Ca, P, F, Al, Sr, and $\mathrm{Si}$ ) of ionomer cements and enamel white spot formation.

\section{Methodology Cavity Preparation and Placement of Restorative Materials}

Groups of 15 bovine teeth slabs $(6 \times 6 \times 3 \mathrm{~mm})$ were submerged in acrylic resin mounting blocks (Jet, São Paulo, Brazil) with the vestibular surface facing the glass plate. Silicon carbide abrasive paper of successive grits 600 and 800 - (3M Espe, Monrovia, USA) was used on a polishing machine (Arotec, São Paulo, Brazil) to remove excess resin, thus exposing the enamel area.

The specimens were divided into three groups ( $\mathrm{n}=30$ ) according to Table 1, as follows: a universal restorative resin composite, Filtek ${ }^{\mathrm{TM}} \mathrm{Z} 250$ (3M Espe, Monrovia, USA), and two restorative hand-mixed glass-ionomer cements, Ionomaster $\mathrm{R}^{\mathrm{TM}}$ (Wilcos, Petropolis, Brazil) and Fuji IX'M (GC Corporation, Tokyo, Japan), respectively. Cavities were prepared with $3 \mathrm{~mm}$ diameter spherical diamond burs (KG Sorensen, Rio de Janeiro, Brazil) on the surface of the enamel, $1.5 \mathrm{~mm}$ deep, thus ensuring exposure of the dentin. Cavity preparations for both glass ionomer and composite restorations were etched and dried according to the manufacturer's instructions. The adhesive system used for the resin composite was Adper Single Bond ${ }^{\mathrm{TM}} 2$ (3M Espe, Monrovia, USA) according to the manufacturer's instructions.

Table 1. Samples of composite resins (CR) and glass-ionomer cement $(\mathrm{GIC})$ in control $(\mathrm{C})$ and experimental $(\mathrm{E})$ conditions

\begin{tabular}{|c|c|c|}
\hline Groups ( $n=15)$ & $\begin{array}{l}\text { Restorative } \\
\text { materials }\end{array}$ & Condition \\
\hline Filtek-C (control group) & Filtek $^{T M}$ Z250 & $\begin{array}{l}\text { Remineralizing } \\
\text { saliva* }\end{array}$ \\
\hline Filtek-E (experimental group) & Filtek $^{T M} \mathrm{Z} 250$ & pH Cycling \\
\hline lonomaster-C (control group) & $\begin{array}{l}\text { lonomaster } \\
R^{\mathrm{TM}}\end{array}$ & $\begin{array}{c}\text { Remineralizing } \\
\text { saliva* }^{*}\end{array}$ \\
\hline lonomaster-E (experimental group) & $\begin{array}{l}\text { lonomaster } \\
R^{\mathrm{TM}}\end{array}$ & pH Cycling \\
\hline Fuji-C (control group) & Fuji IX $X^{\mathrm{TM}}$ & $\begin{array}{l}\text { Remineralizing } \\
\text { saliva* }^{*}\end{array}$ \\
\hline Fuji-E (experimental group) & Fuji IX ${ }^{\top M}$ & pH Cycling \\
\hline
\end{tabular}

*Groups submitted to neutral remineralizing artificial saliva

\section{Demineralizing/Remineralizing Cariogenic Challenge}

A $25 \mathrm{~mm}^{2}$ area of the restoration and surrounding enamel of each slab was left exposed, and the entire residual area of the blocks was coated with red nail varnish (Risqué, São Paulo, Brazil). Negative postcycling control groups $(n=45)$ were kept in artificial remineralizing saliva, whereas the experimental group was submitted to $\mathrm{pH}$ cycling, alternating for 8 hours in demineralizing saliva and then 16 hours in remineralizing saliva, for 8 days. ${ }^{18}$

The experimental groups were submitted daily to demineralizing saliva adjusted to $\mathrm{pH} 5.0$ with sodium hydroxide in $400 \mathrm{~mL} 0.1 \mathrm{M}$ acetate buffer - pH 5.0 - containing $1.28 \mathrm{mM} \mathrm{Ca}, 0.74 \mathrm{mM} \mathrm{P}_{\mathrm{i}}$, and $0.03 \mu \mathrm{g} \mathrm{F} / \mathrm{mL}$ (Vetec, Rio de Janeiro, Brazil) ${ }^{18,19}$ for 8 hours. After the samples were washed with deion- 
ized water, they were kept in remineralizing saliva adjusted to $\mathrm{pH} 7.0$ in $200 \mathrm{~mL}$ solution containing 1.5 $\mathrm{mM} \mathrm{Ca}, 0.9 \mathrm{mM} \mathrm{P}_{\mathrm{i}}, 150 \mathrm{mM} \mathrm{KCL}, 0.05 \mu \mathrm{g} \mathrm{F} / \mathrm{mL}$, and $0.1 \mathrm{M}$ Tris buffer - (Vetec, Rio de Janeiro, Brazil) $)^{17,18}$ for 16 hours, completing a cycle of 24 hours.

During $\mathrm{pH}$ cycling periods, specimens were kept in an incubator (Fanem Ltda., São Paulo, Brazil), at $37^{\circ} \mathrm{C}$, to simulate the oral environment. This procedure was reproduced for a period of 8 days. The procedure used by Moi et al. ${ }^{18}$ was modified as follows: the proportion of demineralizing and remineralizing solutions per area of block was maintained (2:1) with fixed volumes of solution (400 and $200 \mathrm{~mL}$, respectively), and both solutions were replaced by fresh ones on the $4^{\text {th }}$ day. After the $8^{\text {th }}$ day, the blocks were kept in the remineralizing solution for an additional $24 \mathrm{~h}$.

\section{Evaluation of the Caries-Preventive Effect - Occurrence of White Spot Lesion Inhibition Zone}

The caries-preventive effect was evaluated by direct macroscopic observation of the presence of white spot lesions. All enamel surfaces of each group $(n=15)$ were classified by two trained examiners, according to the levels of presence or absence of white spot lesions around the restoration, using four scores ranging from 0 to 3 , as follows: score $0-0 \%$ of white spot lesion; score 1 - area of white spot lesion $<50 \%$; score 2 - area of white spot lesion $>50 \%$; and score 3 - area of white spot lesion $=100 \%$.

\section{Ion Exchange Evaluation - Scanning Electron Microscopy with X-ray Microanalysis (SEM/EDS)}

Hemisectioned samples transverse to the prepared surface were obtained by means of a low-speed diamond saw (Buehler, Lake Bluff, USA) and prepared for SEM, in the same way as biological material. Sectioned surfaces were analyzed on a scanning electron microscope by back-scattered electrons (BSE) at $20 \mathrm{kV}$ voltage, low vacuum mode (45 Pa) and magnification of 500 X (Jeol Ltd., Tokyo, Japan).

Chemical analysis for the assessment of relative mineral content of enamel and restorative materials was performed by energy-dispersive X-ray spectroscopy (Jeol Ltd., Tokyo, Japan) with EDX Link. The energy calibration was performed using the internal standards for the equipment. The content of the $\mathrm{Ca}$, $\mathrm{P}, \mathrm{F}, \mathrm{Al}, \mathrm{Sr}$, and $\mathrm{Si}$ structural elements was assessed, and the $\mathrm{Ca} / \mathrm{P}$ ratio was calculated.

Analyses were performed about $1 \mathrm{~mm}$ from the dentin/enamel interface, and four points were considered for EDX analysis: (MB) material bulk, (MI) material interface, (EI) enamel interface, and (EB) enamel bulk (Figure 1). The interface areas were chosen to evaluate whether any alteration in ionic exchange could be expected in response to a cariogenic challenge. The bulks of material and teeth (depth $<50$ $\mu \mathrm{m})^{13}$ were also analyzed to investigate ion exchange and incorporation in the area surrounding the teeth.

\section{Statistical analysis}

Score values of white spot formation and EDX semi-quantitative analysis were entered in the statistical program SPSS 16.0 (SPSS Inc., Chicago, USA). The white spot scores from the restorative materials were submitted to the Kruskal-Wallis and the MannWhitney tests. The EDX values from the four points (MB, MI, EI, and EB) were submitted to ANOVA and post hoc Tukey tests for each restorative material, before and after $\mathrm{pH}$ cycling. The correlation between white spot scores and ions, at the two enamel points (EI and EB), was evaluated by the Pearson correlation test. Statistical tests were performed with a confidence interval of $95 \%(p<0.05)$.

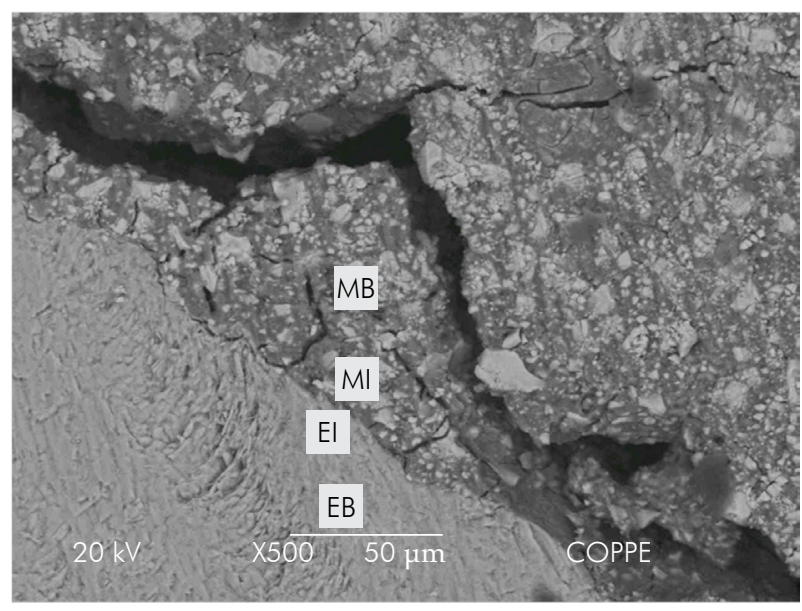

Figure 1. Fuji IX ${ }^{\mathrm{TM}}$ group SEM image with representative EDX points: (MB) material bulk; (MI) material interface; (EI) enamel interface; (EB) enamel bulk. 


\section{Results}

\section{Occurrence of White Spot Lesions}

Score values of white spot lesions are shown in Table 2. Both Ionomaster $\mathrm{R}^{\mathrm{TM}}$ and Fuji IX ${ }^{\mathrm{TM}}$ glass ionomers showed relatively minor mineral loss when submitted to $\mathrm{pH}$ cycling, in comparison with Filtek ${ }^{\mathrm{TM}}$ Z250 composite resin.

Statistical significance was observed between the control and the $\mathrm{pH}$ cycling groups for Filtek ${ }^{\mathrm{TM}} \mathrm{Z} 250$ $(p<0.001)$, Ionomaster $\mathrm{R}^{\mathrm{TM}}(p=0.016)$, and Fuji IX $\mathrm{I}^{\mathrm{TM}}$ $(p=0.001)$. The Filtek ${ }^{\mathrm{TM}} \mathrm{Z} 250$ group presented the highest scores, i.e., $2(46.7 \%)$ and 3 (26.7\%). Filtek ${ }^{\mathrm{TM}}$ Z250 presented a less preventive effect than Ionomaster $\mathrm{R}^{\mathrm{TM}}(p<0.001)$ and Fuji IX ${ }^{\mathrm{TM}}(p=0.004)$. However, the glass ionomers presented a similar preventive effect $(p=0.051)$.

\section{Scanning Electron Microscopy with X-ray microanalysis (SEM/EDX)}

Cracks were observed in the glass ionomers, caused by the vacuum required to perform the SEM and EDX analysis; however, the inorganic content remained intact. Since the presence of cracks may influence the mineral measurements, especially in ionomeric materials, in which this situation occurs more frequently, the cracked areas were excluded from analysis and only continuous regions were assessed, to avoid any bias. Table 3 presents a descriptive analysis of the relative mineral content of Ionomaster $\mathrm{R}^{\mathrm{TM}}$ and Fuji $\mathrm{IX}^{\mathrm{TM}}$, measured by EDX analysis. Fuji IX ${ }^{\mathrm{TM}}$ inorganic content presented a reduced percentage weight of $\mathrm{F}$, $\mathrm{Na}, \mathrm{P}, \mathrm{K}$, and $\mathrm{Ca}$, compared with Ionomaster $\mathrm{R}^{\mathrm{TM}}$.
Filtek $^{\mathrm{TM}} \mathrm{Z} 250$ (Table 4) was used as a control for ionomeric materials. It was possible to identify lower Ca content in the enamel interface than in the enamel bulk (Figure 1), probably due to the enamel etch conditioning step of the restoration procedure. Furthermore, after $\mathrm{pH}$ cycling, Ca content in enamel bulk decreased, indicating demineralization, and Sr, F, and $\mathrm{Al}$ were not identified in this composite group. All of these situations together could explain the greater enamel white spot formation in this group (Table 2). In Fuji IX ${ }^{\mathrm{TM}}$, Ca content in the enamel bulk apparently decreased after $\mathrm{pH}$ cycling, and F content also decreased. In terms of the cariogenic challenge, the Ca content in both EI and EB was lower than in the control group; however $\mathrm{F}, \mathrm{Al}$, and $\mathrm{Sr}$ content was detected, as shown in Figure 2A-F. It should be pointed out that $\mathrm{Sr}, \mathrm{F}$, and $\mathrm{Al}$ content was already greater in the enamel structure of the control groups. Nevertheless, Sr content was higher for the control groups of all the materials at EI and EB $(p>0.05)$.

In terms of the $\mathrm{pH}$ cycling groups, Sr content in the enamel interface was significantly higher than in the composite group only for Fuji IX ${ }^{\mathrm{TM}}(p=0.016)$, whereas both Ionomaster $\mathrm{R}^{\mathrm{TM}}$ and Fuji IX ${ }^{\mathrm{TM}}$ showed a significantly higher $\mathrm{Sr}$ content compared with the Filtek $^{\mathrm{TM}} \mathrm{Z} 250$ composite $(p=0.001$ and $\mathrm{p}=0.010$, respectively) in the enamel bulk. The Ionomaster $R$ $\mathrm{pH}$ cycling group showed a significantly higher $\mathrm{F}$ content in enamel bulk $(p=0.013)$, compared with Filtek $^{\mathrm{TM}} \mathrm{Z} 250$ and Fuji IX ${ }^{\mathrm{TM}}$.

Both ionomeric materials presented similar mineral content (Table 3). In general, a decrease in the

Table 2. $\mathrm{pH}$ cycling score values of white spot lesions for experimental groups with median scores and interquartiles of restorative materials

\begin{tabular}{|c|c|c|c|}
\hline \multirow[b]{2}{*}{ Scores } & \multicolumn{3}{|c|}{ Material } \\
\hline & FiltekTM Z250a & lonomaster $\mathrm{R}^{\mathrm{TM}} \mathrm{b}$ & Fuji IX ${ }^{T M} \mathrm{C}$ \\
\hline 0 & $0.0 \%$ & $66.7 \%$ & $33.3 \%$ \\
\hline 1 & $26.7 \%$ & $33.3 \%$ & $26.7 \%$ \\
\hline 2 & $46.6 \%$ & $0.0 \%$ & $33.3 \%$ \\
\hline 3 & $26.7 \%$ & $0.0 \%$ & $6.7 \%$ \\
\hline Median scores (interquartile) & $2(1)$ & $0(1)$ & $1(2)$ \\
\hline $\mathrm{p}$-value (before $\mathrm{x}$ after $\mathrm{pH}$ cycling) & $<0.001$ & 0.016 & 0.001 \\
\hline $\mathrm{p}$-value (experimental conditions) & $\begin{array}{c}a \times b=<0.001 \\
a \times c=0.004\end{array}$ & $\begin{array}{c}a \times b=<0.001 \\
b \times c=0.051\end{array}$ & $\begin{array}{l}a \times c=0.004 \\
b \times c=0.051\end{array}$ \\
\hline
\end{tabular}

Kruskal-Wallis and Mann-Whitney test $(p<0.05)$.

All groups before $\mathrm{pH}$ cycling presented $100 \%$ of score 0 .

The letters indicate the restorative materials in the statistical analysis. 
A

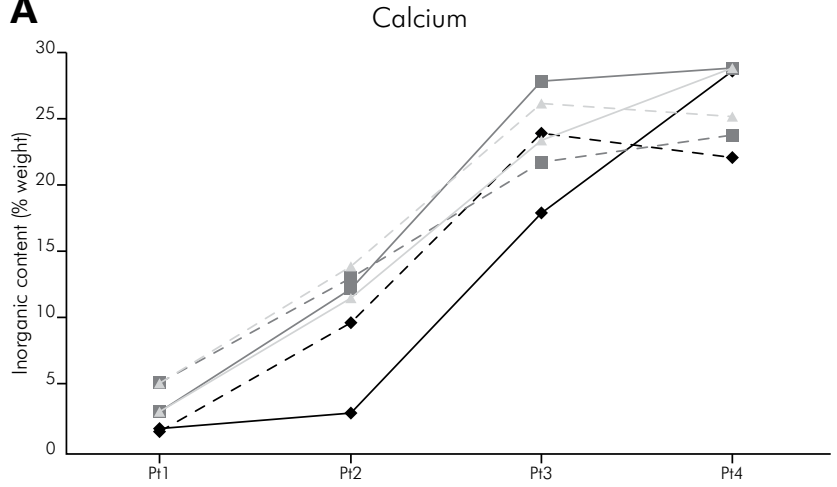

$\rightarrow$ Resin - Ca (control) $\rightarrow$ RM-GIC 1 - Ca (control) $\rightarrow$ RM-GIC 2 - Ca (control)

- - Resin - Ca (pH cycling) - - RM-GIC 1 - Ca (pH cycling) - - - RM-GIC 2 - Ca (pH cycling)

C

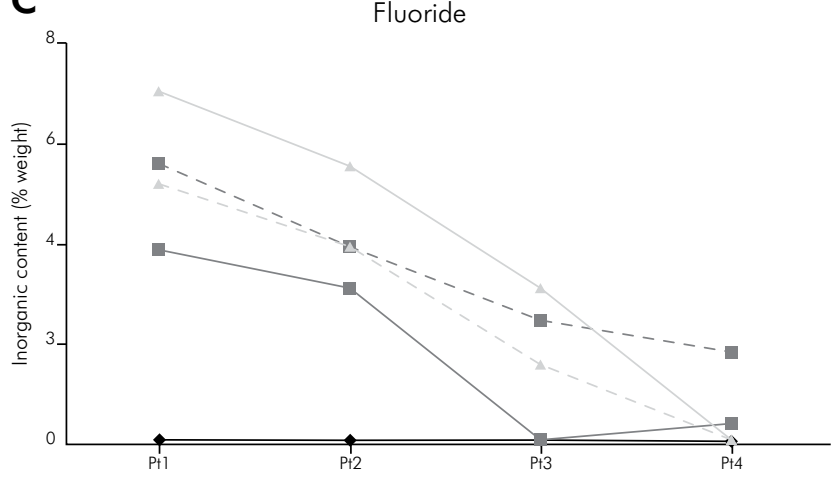

$\longrightarrow$ Resin-Ca (control) $\rightarrow$ RM-GIC 1 - Ca (control) $\longrightarrow$ RM-GIC 2 - Ca (control)

- - Resin - Ca (pH cycling) - - RM-GIC 1 - Ca (pH cycling) - - RM-GIC 2 - Ca (pH cycling)

E

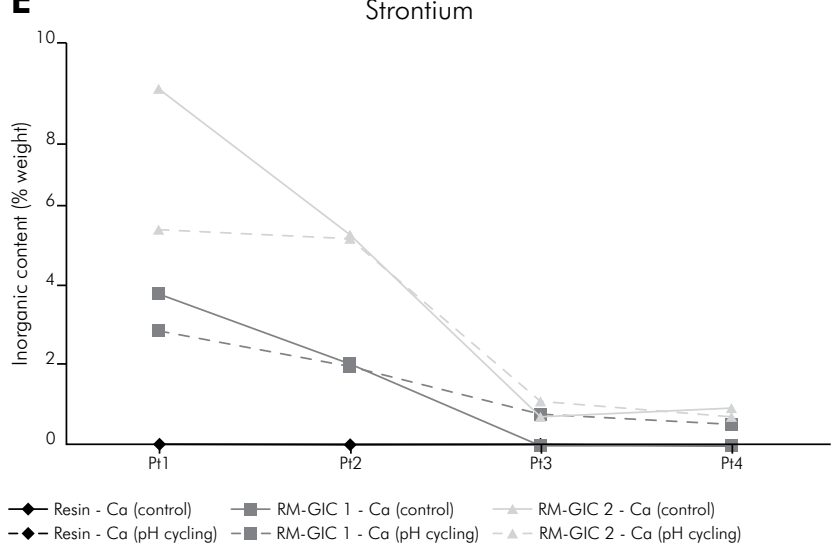

B Phosphorus

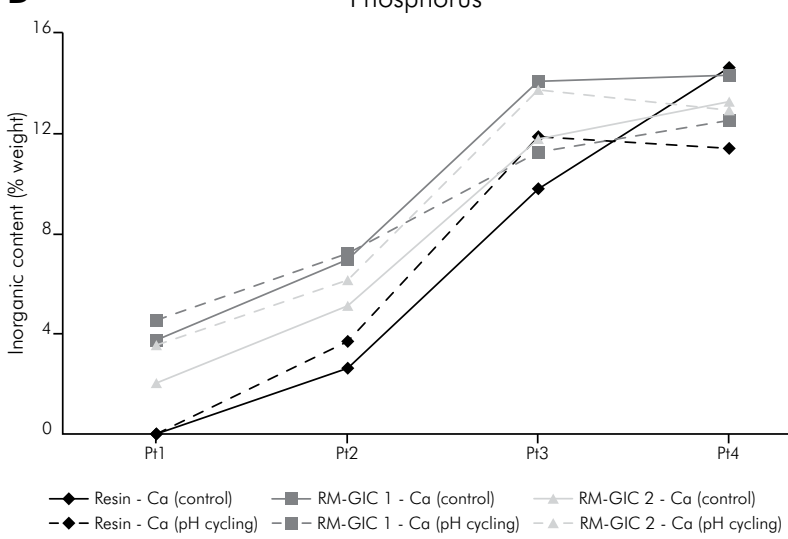

D

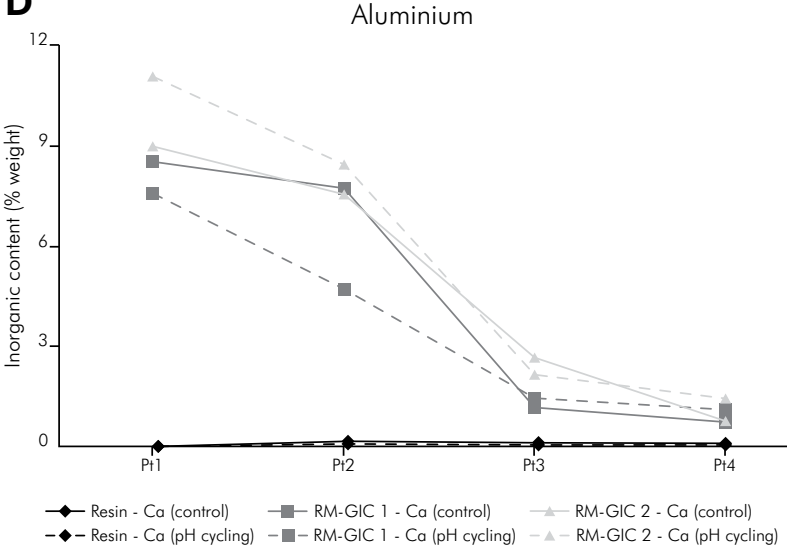

$\mathbf{F}$

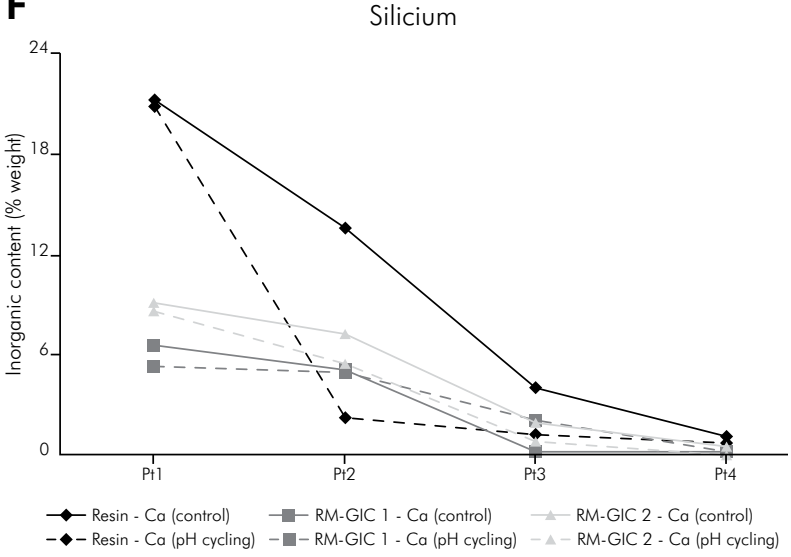

Figure 2. $\mathrm{Ca}(\mathrm{A}), \mathrm{P}(\mathrm{B}), \mathrm{F}(\mathrm{C}), \mathrm{Al}(\mathrm{D}), \mathrm{Sr}(\mathrm{E})$, and $\mathrm{Si}(\mathrm{F})$ content within each material group for control and samples submitted to $\mathrm{pH}$ cycling among points: (MB) material bulk; (MI) material interface; (EI) enamel interface; (EB) enamel bulk.

Table 3. Descriptive compositions of glass (\% weight) of GICs evaluated by EDX

\begin{tabular}{|c|c|c|c|c|c|c|c|c|c|c|}
\hline Glass ionomer composition (\% wt) & 0 & $\mathrm{~F}$ & $\mathrm{Na}$ & $\mathrm{Al}$ & $\mathrm{Si}$ & $P$ & K & $\mathrm{Ca}$ & $\mathrm{Sr}$ & $\mathrm{Ba}$ \\
\hline lonomaster $\mathrm{R}^{\mathrm{TM}}$ & 37.8 & 11.9 & 3.3 & 16.8 & 12.4 & 4.2 & 0.1 & 0.7 & 12.6 & - \\
\hline Fuji IX $X^{\mathrm{TM}}$ & 28.3 & 9.5 & 1.3 & 20.2 & 22.0 & - & - & - & 18.4 & 0.3 \\
\hline
\end{tabular}




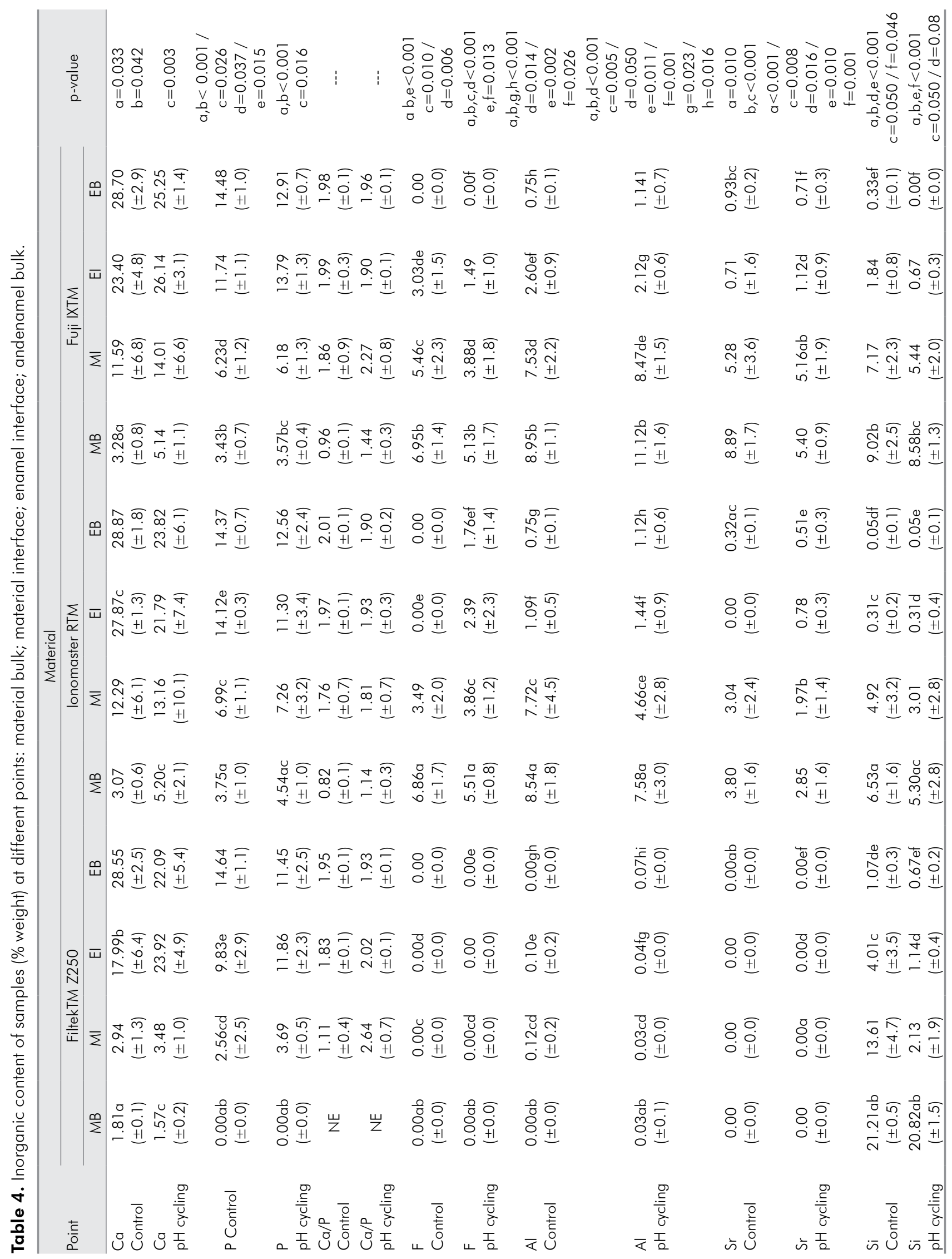


minerals at $\mathrm{MB}, \mathrm{MI}, \mathrm{EI}$, and $\mathrm{EB}$ was observed after $\mathrm{pH}$ cycling. Even after the cariogenic challenge, EI and EB still showed signs of these minerals. The fact that these ions subsisted explains the reduced mineral loss observed in these groups, justifying the lower white spot formation (Table 2).

\section{Statistical differences among restorative materials are represented by letters}

The Pearson's correlation test demonstrated a negative correlation $(p<0.05)$ between the white spot lesions scores and the $\mathrm{Sr}, \mathrm{Al}, \mathrm{F}$, and $\mathrm{Si}$ ions (Table 5). This result demonstrated that white spot lesion formation was inversely proportional to $\mathrm{Sr}, \mathrm{Al}, \mathrm{F}$, and $\mathrm{Si}$ concentrations in enamel interface and bulk.

Table 5. Pearson correlation between white spot scores and ionic content in enamel

\begin{tabular}{lcc}
\hline lon/Localization & R Pearson correlation & $p$-value \\
\hline $\mathrm{Ca} / \mathrm{El}$ & 0.107 & 0.48 \\
$\mathrm{Ca} / \mathrm{EB}$ & -0.152 & 0.32 \\
$\mathrm{P} / \mathrm{El}$ & 0.056 & 0.71 \\
$\mathrm{P} / \mathrm{EB}$ & -0.206 & 0.18 \\
$\mathrm{Sr} / \mathrm{El}$ & -0.402 & 0.01 \\
$\mathrm{Sr} / \mathrm{EB}$ & -0.431 & $<0.01$ \\
$\mathrm{Al} / \mathrm{El}$ & -0.391 & 0.01 \\
$\mathrm{Al} / \mathrm{EB}$ & -0.406 & 0.01 \\
$\mathrm{~F} / \mathrm{El}$ & -0.419 & $<0.01$ \\
$\mathrm{~F} / \mathrm{EB}$ & -0.433 & $<0.01$ \\
$\mathrm{Si} / \mathrm{El}$ & -0.465 & 0.01 \\
$\mathrm{Si} / \mathrm{EB}$ & -0.536 & $<0.01$ \\
\hline
\end{tabular}

\section{Discussion}

It has been widely reported in the literature that GICs show less enamel demineralization caused by cariogenic challenge, in comparison with resin composite material. ${ }^{20,21,22}$ This preventive effect has been vastly discussed in the literature. ${ }^{3,4,11,13}$ It is commonly associated with the different amounts of fluoride content between these materials and the fluoride exchange among glass-ionomer cements and teeth. The current study showed that other inorganic exchanges occur in addition to that of fluoride between glassionomer cements and the mineral content of teeth. Furthermore, it seems that these exchanges are also important for enamel structure reinforcement. The formation of more insoluble apatites, such as strontium-apatite, fluorapatite, and hydroxy-fluorapatite, enhances protection against caries. In addition, under acidic conditions, a much greater number of ions are released from the glass-ionomer cement, and the high release rates are sustained..$^{23,24}$ This dynamic is crucial for caries prevention.

The difference in the ionic dynamics of both GIC groups may be related to the inorganic glass composition. The basicity of the glasses ensured by sufficient replacement of silicon with aluminum in the cement matrix could play an important role in the bioactivity of cement and ion incorporation in the teeth. The apparent exchange of $\mathrm{Ca}$ and $\mathrm{Sr}$ at the restoration interface can be expected as a result of an equilibrium-driven diffusion. ${ }^{13}$ The relatively high diffusion of Sr content in the enamel bulk under $\mathrm{pH}$ cycling is probably related to the bioactivity of Fuji IX glasses. Their composition is based on glasses with extensive substitution of calcium by strontium, and their advantage is that strontium has potential anticariogenic properties, as demonstrated in the current study, where strontium had a preventive effect in reducing white spot formation. The explanation for this substitution is the slightly larger ionic radius of strontium, in comparison with calcium (113 pm compared with 99 pm). ${ }^{25,26}$

In addition to Sr uptake, Fuji IX ${ }^{\mathrm{TM}}$ maintained greater amounts of Ca content in the enamel interface and bulk during neutral (control) and acidic conditions ( $\mathrm{pH}$ cycling). Ionomaster $\mathrm{R}^{\mathrm{TM}}$ had a greater amount of F content in the bulk material, and showed a general decrease in the inorganic content of enamel (EI and $\mathrm{EB}$ ) in the $\mathrm{pH}$ cycling group. Despite this occurrence, the decrease in Ca content was not significant in the GIC groups (Table 2). The only significant loss of Ca content was observed in the Filtek ${ }^{\mathrm{TM}} \mathrm{Z} 250$ control group $(p<0.042)$, presumably due to a phosphoric acid conditioning process, which could explain the low correlation with white spot prevention. In regard to the $\mathrm{pH}$ cycling groups, the $\mathrm{F}$ content of Ionomaster $\mathrm{R}^{\mathrm{TM}}$, at both EI and EB, was higher than that of Fuji $\mathrm{IX}^{\mathrm{TM}}$. However, the $\mathrm{Ca}, \mathrm{P}$, and $\mathrm{Sr}$ content of Ionomaster $\mathrm{R}$ was lower than that of Fuji IX ${ }^{\mathrm{TM}}$, at both EI and EB. Considering the better preventive effect against caries of $\mathrm{F}$, and its correlation with white spot pre- 
vention, one can suppose that $\mathrm{F}$ was an important ion involved in caries prevention (Table 5).

Surfaces were examined using a visual macroscopic scale to evaluate the caries-preventive effect. Despite the limitation of this method in showing quantitative mineral loss values, it allowed a qualitative distinction of the caries-preventive effect among different materials, as in previous studies. ${ }^{19,20}$ A visual method was chosen because the aim of this study was not to quantify the mineral loss, but rather, to make a qualitative macroscopic evaluation of the enamel, by analyzing white spot lesion formation under a cariogenic challenge, and to identify the possible influence of restorative material minerals on this formation. The presence of $\mathrm{Al}$ in the enamel structure of GIC groups may be explained by the Wilson ${ }^{27}$ postulate of complex species occurrence of complex ions $\mathrm{AlF}^{2-}$ and $\mathrm{AlF}_{2}{ }^{-}$among the ions leached

\section{References}

1. Amaral MT, Guedes-Pinto AC, Chevitarese O. Effects of a glass-ionomer cement on the remineralization of occlusal caries--an in situ study. Braz Oral Res. 2006 Apr-Jun;20(2):91-6.

2. Fusayama $T$. Two layers of carious dentin; diagnosis and treatment. Oper Dent. 1979 Spring;4(2):63-70.

3. McCabe JF, Yan Z, Al Naimi OT, Mahmoud G, Rolland SL. Smart materials in dentistry--future prospects. Dent Mater J. 2009 Jan;28(1):37-43.

4. Smales RJ, Gao W. In vitro caries inhibition at the enamel margins of glass ionomer restoratives developed for the ART approach. J Dent. 2000 May;28(4):249-56.

5. Gandolfi MG, Chersoni S, Acquaviva GL, Piana G, Prati C, Mongiorgi R. Fluoride release and absorption at different $\mathrm{pH}$ from glass-ionomer cements. Dent Mater. 2006 May;22(5):441-9.

6. Massler M. Changing concepts in the treatment of carious lesions. Br Dent J. 1967 Dec 5;123(11):547-8.

7. Okada K, Tosaki S, Hirota K, Hume WR. Surface hardness change of restorative filling materials stored in saliva. Dent Mater. 2001 Jan;17(1):34-9.

8. Yip HK, To WM. An FTIR study of the effects of artificial saliva on the physical characteristics of the glass ionomer cements used for art. Dent Mater. 2005 Aug;21(8):695-703.

9. Smales RJ, Fang DT. In vitro effectiveness of hand excavation of caries with the ART technique. Atraumatic restorative treatment. Caries Res. 1999 Nov-Dec;33(6):437-40.

10. Ngo H. Glass-ionomer cements as restorative and preventive materials. Dent Clin North Am. 2010 Jul;54(3):551-63. from glass ionomers. The similarity in the release and absorption behavior of aluminum and fluoride may be significant. Whether this complex occurrence is significant in influencing the clinical effectiveness of fluoride is not known, and is an important topic for further research.

\section{Conclusion}

The ionomer cements presenting a greater percentage of fluoride, aluminum, and strontium incorporated in the enamel structure proved effective in white spot lesion prevention around restorations.

\section{Acknowledgments}

The authors aknowlwdge Professor Tsuneharu Ogasawara (in memoriam) for his valuable help and the Laboratório Multiusuário de Microscopia Eletrônica e Microanálises (COPPE/UFRJ) for technical support.

11. Ngo HC, Mount G, Mc Intyre J, Tuisuva J, Von Doussa RJ. Chemical exchange between glass-ionomer restorations and residual carious dentine in permanent molars: an in vivo study. J Dent. 2006 Sep;34(8):608-13.

12. Nicholson JW. Chemistry of glass-ionomer cements: a review. Biomaterials. 1998 Mar;19(6):485-94.

13. Ab-Ghani Z, Ngo H, McIntyre J. Effect of remineralization/ demineralization cycles on mineral profiles of Fuji IX Fast in vitro using electron probe microanalysis. Aust Dent J. 2007 Dec;52(4):276-81.

14. Dunne SM, Goolnik JS, Millar BJ, Seddon RP. Caries inhibition by a resin-modified and a conventional glass ionomer cement, in vitro. J Dent. 1996 Jan-Mar;24(1-2):91-4.

15. Forsten L. Short- and long-term fluoride release from glass ionomers and other fluoride-containing filling materials in vitro. Scand J Dent Res. 1990 Apr;98(2):179-85.

16. Takahashi K, Emilson CG, Birkhed D. Fluoride release in vitro from various glass ionomer cements and resin composites after exposure to NaF solutions. Dent Mater. 1993 Nov;9(6):350-4.

17. Tam LE, Chan GP, Yim D. In vitro caries inhibition effects by conventional and resin-modified glass-ionomer restorations. Oper Dent. 1997 Jan-Feb;22(1):4-14.

18. Moi GP, Tenuta LM, Cury JA. Anticaries potential of a fluoride mouthrinse evaluated in vitro by validated protocols. Braz Dent J. 2008;19(2):91-6. 
19. Queiroz CS, Hara AT, Paes Leme AF, Cury JA. pH-cycling models to evaluate the effect of low fluoride dentifrice on enamel de- and remineralization. Braz Dent J. 2008;19(1):21-7.

20. Fidalgo TKS, Pithon MM, Santos RL, de Alencar NA, Abrahao AC, Maia LC. Influence of topical fluoride application on mechanical properties of orthodontic bonding materials under pH cycling. Angle Orthod. 2012 Nov;82(6):1071-7.

21. Passalini P, Fidalgo TK, Caldeira EM, Gleiser R, Nojima MC, Maia LC. Preventive effect of fluoridated orthodontic resins subjected to high cariogenic challenges. Braz Dent J. 2010;21(3):211-5.

22. Passalini P, Fidalgo TK, Caldeira EM, Gleiser R, Nojima MC, Maia LC. Mechanical properties of one and two-step fluoridated orthodontic resins submitted to different $\mathrm{pH}$ cycling regimes. Braz Oral Res. 2010 Apr-Jun;24(2):197-203.
23. Czarnecka B, Limanowska-Shaw H, Hatton R, Nicholson JW. Ion release by endodontic grade glass-ionomer cement. J Mater Sci Mater Med. 2007 Apr;18(4):649-52.

24. Rolland SL, McCabe JF, Robinson C, Walls AW. In vitro biofilm formation on the surface of resin-based dentine adhesives. Eur J Oral Sci. 2006 Jun;114(3):243-9.

25. Brudevold F, Tehrani A, Attarzadeh F, Goulet D, van Houte J. Effect of some salts of calcium, sodium, potassium, and strontium on intra-oral enamel demineralization. J Dent Res. 1985 Jan;64(1):24-7.

26. Nicholson JW, Czarnecka B. Review paper: Role of aluminum in glass-ionomer dental cements and its biological effects. J Biomater Appl. 2009 Nov;24(4):293-308.

27. Wilson AD. Acidobasicity of oxide glasses used in glass ionomer cements. Dent Mater. 1996 Jan;12(1):25-9. 